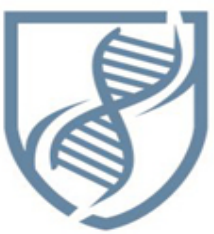

Journal of Bioscience and Applied Research

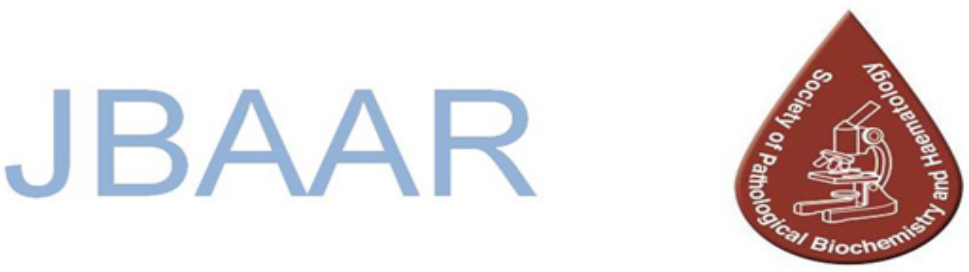

WWW.JBAAR.ORG

\title{
Laboratory evaluation of four insecticides on the mosquito Culiseta longiareolata (Macquart) (Diptera: Culicidae).
}

\author{
Salam S. Teleb and Farag A. Ahmed* \\ Zoology Department, Faculty of Science, Zagazig University, Egypt. \\ (*corresponding author e,mail. faraghexa@ yahoo.com)
}

\begin{abstract} and Topas+Neemrich (co-toxicity factor equaled+40) .The tested insecticides completely inhibited the emergence of adults till $0.0078,0.0625,0.25$ and $1 \mathrm{ppm}$ for lambdacyhalothrin, Marshal, Topas and Neemrich, respectively, and the emergence of adults was inversely proportional to the concentration.
\end{abstract}

The efficacy of four insecticides belonging to different The control of mosquito at the larval stage is necessary and groups, synthetic pyrethroid (lambdacyhalothrin), efficient in the integrated approach to mosquito carbamate (Marshal), fungicide (Topas) and insect growth management . Resistance to carbamates has been noted in regulator (Neemrich) as well as their joint action were Cx.quinquefasciatus. The use of mixtures to a strategy of tested against $3^{\text {rd }}$ larval instar of Culiseta longiareolata. rotation over time of insecticides with different modes of Based on concentration mortality data $\mathrm{LC}_{50}$ and $\mathrm{LC}_{90}$ action has already made it possible to prevent or to delay values, results obtained showed that $\mathrm{LC}_{50}$ values as the appearance of resistance in the field Martin et observed were $0.09,2.3$, 9.0and $25.0 \mathrm{ppm}$ for al.,(2000).However, mixtures of appropriate dosages of lambdacyhalothrin, Marshal, Neemrich and Topas, unrelated compounds may have better prospects for respectively. The results showed that all mixtures consisted managing resistance effectively than rotations of the types of a $1: 1(\mathrm{v} / \mathrm{v})$ ratio of the $\mathrm{LC}_{25}$ of each compound indicated of compounds. The advantage of mixtures is that each potentiating effect .The highest potentiating effect was insecticide eliminates most insects which are genetically achieved by a mixture of co-toxicity factor equaled+100 susceptible to it, Barnes et al. , (1995) .However,many (lambdacyhalothrin + Neemrich). The lowest potentiating authors have already demonstrated the synergistic effect on effects were obtained from mixtures of Marshal + Topas insect pests of carbamates or organophosphates and

Keywords: Insecticides, Culiseta longiareolata, Diptera Culicidae

\section{Introduction}

Cs. Longiareolata (Macquart), is a biting nuisance mosquito in Egypt, it is a wide spread species and found in a high population density Kirkpartrick ,(1925), Kenawy \& Elsaid ,(1989) and Teleb (1994). Cs.longiareolata is also incriminated as a vector of transmitting Plasmodium Reticulum, the causative organisms of Malta fever Hewitt,(1940) and intermediate host of avian plasmodia , Gutsevich et al.,(1970). Chemical control is an effective strategy used extensively in daily life. (1984) and Roberston \& Smith, (1984) with insects of medical importance, a synergistic effect between pyrethroids and carbamates was reported on larvae of Cx.quinquefasciatus ,Corbel et al ,2003) and adults of Anopheles gambiae Corbel et al ,2002) susceptible to these insecticides.

Insecticide mixtures have been proposed as an important tools for resistance management in different insect pests (Hemingway and Ranson, 2000).This type of potentiation or synergism is explained by the inhibition of esterases ,Bryne and Devonshire (1991) and Montella et al.,(2012) or monooxygenases activity ,Martin et al.,(2003).

The present work was carried out to clarify the toxic effect of four insecticides which are regularly used in fields; lambda-cyhalothrin, Marshal, Topas and Neemrich .The interaction between them against the $3^{\text {rd }}$ larval instar of Cs. Longiareolata and the effects of these insecticides on emergency of adults. 


\section{Materials and Methods}

\section{Mosquito culture}

Cs.longiarolata larvae were collected from wells near Zagazig city in Sharkia Governorate and reared under laboratory conditions $\left(25 \pm 2^{\circ} \mathrm{C}\right.$ and $80 \pm 5 \%$ relative humidity )for several generations .

\section{Insecticides}

Commercial formulations of insecticides used for bioassays are :Pyrethroid (lambda-cyhalothrin) ,Carbosulfan ( Marshal 25\%), Topas (with the active compound Penconazole, is a systemic fungicide) and Neemrich. These chemicals obtained from Syngenta Agro Egypt Company - Egypt.

\section{Larvicidal bioassay}

For each insecticide seven concentrations were prepared by diluting the formulation product with distilled water in plastic cups $(250 \mathrm{ml})$ against the $3^{\text {rd }}$ larval instar of Cs.longiareolata.Twenty five larvae were placed in each cup. The test was carried out at the same conditions of rearing. Larvae were left for $24 \mathrm{~h}$ and mortality was then recorded and compared with control. Moribund larvae were considered dead. Four replicates per concentration were used. WHO Technique (1996) was used for measuring the susceptibility of larvae to given insecticides. Mortality was corrected according to Abbott formula (1925).

\section{Joint action study}

Concentration - mortality curves were established and the $\mathrm{LC}_{25}$ values were determined. Binary mixtures were prepared in proportion to their toxicity equivalents of $\mathrm{LC}_{25}$. The combined action of each mixture was expressed as the co-toxicity factor (C.F), estimated according to the equation given by Sun and Johnson (1960) :

Co - toxicity factor $=(\%$ observed mortality $-\%$ expected mortality $) \times 100$

\%expected mortality

A positive factor of 20 or more is considered potentiation, A negative (-20) or more is considered antagonism , and intermediate values ranging between -20 and +20 indicate only additive effect.

\section{Pupicidal bioassay}

Ten replicates of newly developed pupae were transferred into plastic cups $10 \mathrm{~cm}$ height (4/ cup) containing different concentrations of each of the tested insecticide. The number of emerging adults was observed ,calculated daily and compared with control (untreated ).

\section{Data analysis}

Data obtained from each concentration. Larvicidal bioassay (total mortality) were subjected to probit analysis (Finney, 1971) and $\mathrm{LC}_{25}, \mathrm{LC}_{50}$ and $\mathrm{LC}_{90}$ values were calculated .All results were expressed as mean \pm standard error, and the data were analyzed using student T-test. Results with $\mathrm{p}<0.05$ were considered to be statistically significant.

\section{Rresults}

\section{Larvicidal bioassay}

The results presented in table 1 showed that all insecticides induced mortality on the $3^{\text {rd }}$ larvae of $C s$. longiarolata .On the basis of $\mathrm{LC}_{50}$ values, the larvicidal toxicity of lambda-cyhalothrin was the most potent $\left(\mathrm{LC}_{50}=\right.$ $0.08 \mathrm{ppm})$ followed by $\operatorname{Marshal}\left(\mathrm{LC}_{50}=2.4 \mathrm{ppm}\right)$, $\operatorname{Neemrich}\left(\mathrm{LC}_{50}=8.7 \mathrm{ppm}\right)$ and $\operatorname{Topas}\left(\mathrm{LC}_{50}=24.6\right.$ $\mathrm{ppm}$ ), respectively.Similar trend has also been observed for $\mathrm{LC}_{90}(0.3,11.7,51.7$ and 106.3 for lambda-cyhalothrin, Marshal, Neemrich and Topas, respectively.

\section{Joint action study}

The interaction of binary mixtures of tested insecticides against the $3^{\text {rd }}$ larval instar of $C s$. longiareolata is shown in table 2 . The calculated "cotoxicity factor" exceeded 20; a results accounting to "potentiation effect". All the mixtures exhibited potentiation effect. The highest potentiating effect was for mixtures of co-toxicity factor equaled +100 (lambdacyhalothrin+ Neemrich). The lowest potentiating effects(+40) was obtained from mixtures of Marshal + Topas and Topas + Neemrich.

\section{Pupicidal bioassay}

Data concerning pupicidal activity are shown in table 3.The results revealed that all insecticides caused $100 \%$ complete inhibition of the adult emergence at $0.0078 \mathrm{ppm}$, for Lambda cyhalothrin, 0.0625 for Marshal , 1.0 for Neemrich , $0.25 \mathrm{ppm}$ for Topas.The adult emergence increased by dilution ,Zidan et al., (1997) found that the synthetic pyrothroid, cyphenothrin showed complete inhibition of adult emergence of $C x$. pipiens pupae.

\section{Discussion}

Kawakami,(1989) tested permethrin against $C x$. pipiens larvae and found that $\mathrm{LC}_{50}$ was $0.01 \mathrm{ppm}$. Basset et al., (1997) found that Cx.pipiens subjected to Lambda cyhalthrin did not develop cross resistant to cypermethrin ,this was in contradiction with Xia et al .,(1998) who reported that Cx.pipiens resistance to Lambda-cyhalthrin developed 41 and 28 fold resistance to permethrin and cypermethrin, respectively.

There are several studies on mixture toxicities (particularly pyrethroids with other compounds) in different dipteran insect pests worldwide, Since pyrethroids and organophosphates have different modes of action, their mixtures have commonly been in practice against a variety of pests worldwide for the last many years Ahmad , (2009). Previously it has been assumed that organophosphates, when used in combination with pyrethroids, inhibit the enzymes responsible for metabolic detoxification in different insect pests Martin et al., (2003) .Corbel et al.,(2003) showed that propoxur at $\mathrm{LC}_{50}$ significantly enhanced the insecticidal activity of permethrin. Ali Khan et al., (2013) showed that most of the insecticide mixtures 
Table(1)Efficacy of the four insecticides on the 3rd larval instar of Cs.Longiareolata

\begin{tabular}{|c|c|c|c|c|}
\hline \multirow[b]{2}{*}{ Insecticide } & \multicolumn{3}{|c|}{ Le values (ppm) } & \multirow[b]{2}{*}{ Slope function } \\
\hline & $\mathbf{L c}_{25}$ & $L c_{50}$ & $\mathbf{L c}_{90}$ & \\
\hline lambda-cyhalothrin & $\begin{array}{l}0.04 \\
(0.25-0.45)\end{array}$ & $\begin{array}{l}0.08 \\
(0.04-0.09)\end{array}$ & $\begin{array}{l}0.3 \\
(0.25-0.42)\end{array}$ & $3.6 \pm 0.1$ \\
\hline Marshal & $\begin{array}{l}0.5 \\
(0.1-0.8)\end{array}$ & $\begin{array}{l}2.4 \\
(2.0-3.0)\end{array}$ & $\begin{array}{l}11.7 \\
(10.0-13.0)\end{array}$ & $9.4 \pm 0.6$ \\
\hline Neemrich & $\begin{array}{l}3.7 \\
(3.2-4.0)\end{array}$ & \begin{tabular}{|l}
8.7 \\
$(8.0-0.9)$
\end{tabular} & $\begin{array}{l}51.7 \\
(45.0-60.0)\end{array}$ & $22.5 \pm 0.8$ \\
\hline Topas & $\begin{array}{l}11.0 \\
(9.0-13.0)\end{array}$ & $\begin{array}{l}24.6 \\
(22.0-27.0)\end{array}$ & $\begin{array}{l}106.3 \\
(102.0-108.0)\end{array}$ & $3.6 \pm 0.1$ \\
\hline
\end{tabular}

Values between brackets are $90 \%$ fudicial limits of the corresponding toxicity values. The latter values are estimated from their respective regression lines (LC-P lines).

Table(2)The joint action of four insecticides on the 3rd larval instar of Cs. Longiareolata

\begin{tabular}{|l|l|l|l|}
\hline & $\begin{array}{l}\text { Lc } 2 \text { (ppm) For } \\
\text { Compound Compound } \\
1\end{array}$ & $\begin{array}{l}\text { Observed } \\
\text { mortality } \\
\%\end{array}$ & $\begin{array}{l}\text { Co-Toxicity } \\
\text { Factor }\end{array}$ \\
\hline lambda-cyhalothrin1+ Marshal2 & $\mathbf{0 . 0 4}+\mathbf{0 . 5}$ & $\mathbf{9 0}$ & $\mathbf{+ 8 0}$ \\
\hline lambda-cyhalothrin1+ Neemrich2 & $\mathbf{0 . 0 4}+\mathbf{3 . 7}$ & $\mathbf{1 0 0}$ & $\mathbf{+ 1 0 0}$ \\
\hline lambda-cyhalothrin1+ Topas2 & $\mathbf{0 . 0 4}+11.0$ & $\mathbf{8 5}$ & $\mathbf{+ 7 0}$ \\
\hline Marshal1 + Neemrich2 & $\mathbf{0 . 5}+3.7$ & $\mathbf{8 0}$ & $\mathbf{+ 6 0}$ \\
\hline Marshal1+ Topas & $\mathbf{0 . 8}+11$ & $\mathbf{7 0}$ & $\mathbf{+ 4 0}$ \\
\hline Topas 1+ Neemrich2 & $\mathbf{1 1}+3.7$ & $\mathbf{7 0}$ & $\mathbf{+ 4 0}$ \\
\hline
\end{tabular}

like one pyrethroid with other compounds significantly toxicity of insecticides in a resistant dairy population of increased the toxicity of pyrethroids in the field population Musca domestica L. PLOS ONE 8(4): e60929.

of house flies, Musca domestica L..

In addition, insecticides from pyrethroid and organophosphate classes may be potential or competitive substrates for the same oxidase, as demonstrated by Kulkarni and Hodgson (1980) thus potentiating the toxicity of the insecticide mixture.The pupicidal activity of insecticides was also studied by Fournet et al.,(1993), and Trayler et al .,(1994).

\section{References}

Abbott, W.S. (1925):A method of computing the effectiveness of an insecticide. J. Econ. Entomol., 18: 265267.

Ahmad, M. (2009): Observed potentiation between pyrethroid and organophosphorus insecticides for the management of Spodoptera litura(Lepidoptera:Noctuidae). Crop Protec. 264-268.

Ali,K. ; Hafiz ,A.; Waseem, A.; Sarfraz A. and JongJin L.,(2013):insecticide mixtures could enhance the
Barnes, E.H.; Dobson, R. J. and Barger, I. A. ; (1995):Worm control and antihelmintic resistance: adventures with a model. ParasitolToday 11:56-63

Bisset,J. ; Rordrigues M. ; Soca, A.; Pasteur, N. and Raymond, M.(1997). Cross-resistance to pyrethroid and organophosphrus insecticides in the thouthern house mosquito (Diptera: Culicidae from . Cuba.J.Med. Entomol.,34:244-246.

Bryne,F.J. and Devonshire, A.L. (1991): In vivo inhibition of esterase and acetylcholinesterase activities by profenofos treatment in the tobacco white fly Bemisia tabaci (Genn) implications for routine biochemical monitoring of these enzymes. Pest Biochem .Physiol ; 40:198-204.

Corbel, V.; Chandre,F.; Darriet, F.; Lardeux, F., and Hougard, J.M., (2003):Synergism between permethrin and propoxur against Culex quinquefasciatus mosquito larvae. Med.Vet. Entomol.,17:158-164. 
Table (3) Pupicidal activity of four insecticides on Cs.Longiareolatapupae

\begin{tabular}{|c|c|c|c|c|}
\hline \multirow[b]{2}{*}{ Conc.(ppm) } & \multicolumn{2}{|l|}{ \% Emergency } & \multicolumn{2}{|l|}{ (Mean S.E $)_{*}^{*}$} \\
\hline & Lambdacyhalothrin & Marshal & Neemrich & Topas \\
\hline 1 & 0.0 & 0.0 & 0.0 & 0.0 \\
\hline 0.5 & 0.0 & $\mathbf{0 . 0}$ & $12.5 \pm 3.5^{*}$ & 0.0 \\
\hline 0.25 & 0.0 & 0.0 & $31.3 \pm 3.5 \%$ & 0.0 \\
\hline 0.125 & 0.0 & 0.0 & $* \quad \mathbf{5 0 . 0} \pm 5.1$ & $12.5 \pm 3.5 \%$ \\
\hline 0.0625 & 0.0 & $\mathbf{0 . 0}$ & $75.0 \pm 5.1 \%$ & $31.3 \pm \pm 3.1 *$ \\
\hline 0.0312 & 0.0 & 31.3 $\pm 3.1 *$ & $\mathbf{1 0 0 . 0} \pm 0.0$ & $4305 \pm 3.4 \%$ \\
\hline 0.0156 & 0.0 & $56.3 \pm 3.1 \%$ & - & $56.3 \pm 3.1 *$ \\
\hline 0.0078 & 0.0 & $68.8 \pm 5.9 *$ & - & $75.0 \pm 3.0 *$ \\
\hline 0.0039 & $25.0 \pm 5.1 *$ & $87.5 \pm 3.0 *$ & - & $87.5 \pm 3.6 *$ \\
\hline 0.0018 & $56.3 \pm 5.1 \%$ & $100.0 \pm 0.0$ & _ & $100.0 \pm 0.0$ \\
\hline 0.0009 & $83.3 \pm 3.0 \%$ & - & - & - \\
\hline 0.00045 & $100.0 \pm 0.0$ & - & - & - \\
\hline Control & $100.0 \pm 0.0$ & $100.0 \pm 0.0$ & $100.0 \pm 0.0$ & $100.0 \pm 0.0$ \\
\hline
\end{tabular}

* Significant $\mathrm{P}=0.05$

***esults are the means of ten replicate

Corbel,V.;Darriet,F.;Chandre,F.and Hougard, J.M., (2002):Insecticide mixtures for mosquito net impregnation against malaria vectors. Parasite 9:255-259 .

Finney, D.J.(1971):Probit Analysis. 2nd ed. Cambridge University Press:, London. p. 333.

Fournet,F.C.;Sannier , and Monteny ,N.(1993):Effects of the insect growth regulators OMS2017 pipiensmolestus Forskal collected in Shinjuku-ku, and Diflubenzuron on the reproductive potential of Tokyo.Jap. J. Sanitary-Zool.,40:217-220. Aedesaegypti J .Amer.Mosq.Control Assoc. 9:426-430.

Gutsevich,A.V.;Monochodskil,A.S. and Shtakel Berg,A.A. (1970):Insecta Diptera, Vol.pt.4Mosquitoes (FamilyCulicidae).Funa ,Izdat,Nauka,348pp.
Hemingway ,J, .andRanson, H. (2000) :Insecticide resistance in insect vectors of human disease. Annu.Rev.Entomol., 45:371-391.

Hewitt,R.(1940): Bird malaria .Amer. J. Hyg. ,Monographic Series No. 15:228pp

Kenawy,M.A. and Elsaid ,S.(1989) : Characterization of culicinemosquito habitats in the Nile Delta , Egypt .Proc.Int. Conf. Comp. Res. and Dem.:211231.

Kirkpartick,T.W. (1925): The mosquitoes ofEgypt . Egyptian Gov. Antimalaria commission,Gov. press ,224. 
Koziol,S.F. and Witkowski, J.F., (1982): Synergism studies with binary mixtures of permethrin plus methyl parathion, chlorpyrifos, andmalathion on European cornborer larvae. J. Econ Entomol.75:28-30.

Kulkarni,A.P.,and Hodgson ,E; (1980) Metabolism of insecticides by mixed functionoxidase systems. Pharmacol.Ther., 8:379-475.

Martin ,T.;Ochou, G.O., Hala-Nklo, F., Vassal, J.M. and Vayssaire,M., (2000):Pyrethroid resistance in the cotton bollworm, Helicoverpa armigera, in West Africa. Pest. Manag.Sci.56:549-554.

Martin ,T.;Ochou, O.G.;Vaissayre,M.; Fournier, D., (2003):Organophosphorus insecticides synergise pyrethroids in the resistant strain of cotton bollworm,Helicoverpaarmigera (Lepidoptera: Noctuidae) from West Africa. J .Econ. Entomol.92: 468-474.

Montella,I.R.;Schama,R., and Valle, D. (2012) :The classification of esterases: animportant gene family involved in insecticide resistance - A Review. Mem.Inst.Oswaldo Cruz Rio de Janeiro, 107: 437-449.

Ozaki, K.; Sasaki, Y. and Kassai,T., (1984):The insecticidal activity ofmixtures of pyrethroids and organophosphates or carbamatesagainst the insecticideresistant green rice leafhopper,NephotettixcincticepsUhler. Nihon NoyakuGakkaishi (J.Pestic.Sci.) 9:67-72 .

Roberston,J.L. and Smith, K.C., (1984):Joint action of pyrethroids withorganophosphorus and carbamate insecticides applied towestern spruce budworm (Lepidoptera: Tortricidae). J. Econ.Entomol.,77:16-22 .

Sun, Y.P., and Johnson ,E.R.,(1960): Analysis of joint action of insecticides against house flies. J .Econ .Entomol.; 53:887-92.
Teleb,S.S. (1994): Ecological and biological studies on some mosquito species in species in Sharkia Governorate Ph. D Thesis,Faculty of Science ,Zagazig University .

Trayler, K.M.; Pinder, A.M and Davis J.A.(1994):Evaluation of the juvenile hormone mimic pyriproxyfen(S-31183)against nuisance Chironomids (Diptera:Chironomidae ), with particular emphasis on Polpedlumnubifer ( Skuse).J .Aust.Ento.Soc., 33(2):127130.

WHO (1996): Report of the WHO informal consultation on the evaluation on the testing of insecticides CTD/WHO PES/IC/96, 1:69.

Xia,C.J.; Yan ,Z.T.; Lihua,Z.D.;Yan ,D.; Baolin ,L.; Cheng,J.X.; Zhu ,T.Y.,;Lu ,B.L. and Dong,Y.D.(1998): Selection of resistant strain of Culexpipienspallens to Lambda- cyhalthrin and its cross-resistance to other insecticides.Acta-Parasitologica-et Medica Entomologica Sinica, 5:106-111.

Zidan, H.Z.; Teleb, S.S. and Amed,F.A.,(1997):

Toxicity and biological activities of certain insecticides on Culexpipiens L. (Diptera: Culicidae) .Ain Shams Science Bull. V.35:275-286. 